\title{
Electron Paramagnetic Resonance and Photoluminescence Investigation of Europium Local Structure in Oxyfluoride Glass Ceramics Containing $\mathrm{SrF}_{2}$ Nanocrystals
}

\author{
A. Antuzevics*, M. Kemere, G. Krieke, R. Ignatans \\ Institute of Solid State Physics, University of Latvia \\ * Corresponding author \\ E-mail: andris.antuzevics@gmail.com
}

\begin{abstract}
Different compositions of europium doped aluminosilicate oxyfluoride glass ceramics prepared in air atmosphere have been studied by electron paramagnetic resonance (EPR) and optical spectroscopy methods. X-ray diffraction (XRD) and transmission electron microscopy (TEM) measurements show presence of homogenously distributed $\mathrm{SrF}_{2}$ nanocrystals after the heat treatment of the precursor glass. Efficient $\mathrm{Eu}^{3+}$ incorporation in the high symmetry environment of glass ceramics is observed from the photoluminescence spectra. EPR spectra indicate $\mathrm{Eu}^{3+} \rightarrow \mathrm{Eu}^{2+}$ reduction upon precipitation of crystalline phases in the glass matrix. For composition abundant with $\mathrm{Eu}^{2+}$ in the glassy state such behaviour is not detected. Local structure around europium ions is discussed based on differences in chemical compositions.
\end{abstract}

Keywords: electron paramagnetic resonance; luminescence; oxyfluoride; transparent glass ceramics; europium ions.

\section{Introduction}

Glass ceramics (GCs) are considered as excellent optical materials due to their transparency in wide spectral range, high mechanical and thermal stability and good solubility of dopant ions in the crystalline phase. [1] In particular, rare-earth doped GCs have been studied extensively for potential application in white light emitting diodes (WLEDs). [2-8]

Properties of luminescence centres are inseparably connected with their local structure, therefore, it needs to be studied and understood thoroughly to tailor an efficient phosphor for desired applications. For example, in europium doped systems, depending on the valence state, emissions may originate either from $4 f-4 f$ transitions $\left(\mathrm{Eu}^{3+}\right)$ or from $5 d-4 f$ transitions $\left(\mathrm{Eu}^{2+}\right)$. 
The intra- $4 f$ shell transitions are relatively well shielded from the surrounding ligand field making $\mathrm{Eu}^{3+}$ narrow luminescence line positions nearly independent of the host material. The intensity ratio of electric dipole $\left({ }^{5} \mathrm{D}_{0} \rightarrow{ }^{7} \mathrm{~F}_{2}\right)$ and magnetic dipole $\left({ }^{5} \mathrm{D}_{0} \rightarrow{ }^{7} \mathrm{~F}_{1}\right)$ allowed transitions also called as Red/Orange (R/O) ratio, on the other hand, strongly depends on the local site symmetry, thus, $\mathrm{Eu}^{3+}$ ions may be used as optical probes to study the local structure around luminescence centres. [9] Shift of R/O ratio has been observed in GCs after annealing the precursor glasses when $\mathrm{Eu}^{3+}$ enters $\mathrm{BaCl}_{2}$ [3], $\mathrm{SrF}_{2}$ [10], $\mathrm{LaF}_{3}[11], \mathrm{NaLuF}_{4}[12]$ and other crystalline phases.

Contrary to the fixed $\mathrm{Eu}^{3+}$ narrow line luminescence, the position of the wide band resulting from $5 d-4 f$ transitions of the $\mathrm{Eu}^{2+}$ ions is highly sensitive to the surrounding crystal field. By choosing a suitable host we can adjust luminescence from blue in $\mathrm{SrF}_{2}$ [13] to green in $\mathrm{SrAl}_{2} \mathrm{O}_{4}$ [14] or even red in $\mathrm{SrS}$ [15]. The ground state of $\mathrm{Eu}^{2+}$ is paramagnetic and thus additional information regarding local interactions can be obtained via electron paramagnetic resonance (EPR) spectroscopy techniques. Magnetic resonance spectra of europium ions in glasses have been studied extensively [16-19], however, there is a lack of EPR information in literature about the incorporation of $\mathrm{Eu}^{2+}$ ions into the crystalline phase of GCs.

Previous photoluminescence studies have shown that in tellurite GC the initial trivalent Europium enters $\mathrm{SrF}_{2}$ crystallites in the ${ }^{3+}$ state [10], whereas in oxyfluoride GC heat treatment and precipitation of $\mathrm{SrF}_{2}$ leads to reduction of europium ions to the ${ }^{2+}$ state [20]. Sample preparation in reducing atmosphere can lead to abundance of $\mathrm{Eu}^{2+}$ in the precursor glass resulting in broad blue emission, which is further intensified after crystallization of $\mathrm{SrF}_{2}$ particles in the matrix. [21] Reduction of europium for glasses prepared under air atmosphere has also been investigated in systems containing $\mathrm{CaF}_{2}$ and $\mathrm{BaF}_{2}$. $[19,22,23]$

In this work we study properties of europium ions in two novel aluminosilicate oxyfluoride compositions containing $\mathrm{SrF}_{2}$. For one composition reduction of europium is achieved by the heat treatment of the precursor glass, whereas second composition is already abundant with $\mathrm{Eu}^{2+}$ in the glassy state. Detailed EPR spectra analysis for each composition suggests different possible local environments around europium ions and previously unreported paramagnetic centres in GCs are observed here. PL 
spectra indicate efficient incorporation of $\mathrm{Eu}^{2+}$ in various silicate phases present in GCs. The results obtained here provide a better knowledge about properties of various europium centres in GCs and could contribute to the development of future optical materials.

\section{Materials and methods}

Glasses were prepared from initial powder compositions $40 \mathrm{SiO}_{2}-25 \mathrm{Al}_{2} \mathrm{O}_{3}-15 \mathrm{Na}_{2} \mathrm{CO}_{3}-19 \mathrm{SrF}_{2}-1 \mathrm{EuF}_{3}$ (S1) and $50 \mathrm{SiO}_{2}-20 \mathrm{Al}_{2} \mathrm{O}_{3}-10 \mathrm{NaF}-19 \mathrm{SrF}_{2}-1 \mathrm{EuF}_{3}(\mathrm{~S} 2)$ (in mol\%) by the conventional melt quenching technique. A total of $8 \mathrm{~g}$ of high purity chemicals were weighed, mixed and melted in a covered alumina crucible at $1450 \pm 10{ }^{\circ} \mathrm{C}$ in air atmosphere. The melt was quenched by pouring it onto a stainless steel plate at room temperature. The GCs were obtained by an isothermal treatment (1 hour) of the precursor glass (PG). For comparative analysis a polycrystalline $\mathrm{SrF}_{2}: \mathrm{Eu}^{2+}$ sample was synthesized by heating of $99 \mathrm{SrF}_{2}-1 \mathrm{EuF}_{3}$ at $1000 \pm 10{ }^{\circ} \mathrm{C}$ in $\mathrm{CO}$ atmosphere. In this article $\mathrm{S} 1$ composition sample heated at $650 \pm$ $10{ }^{\circ} \mathrm{C}$ will be referenced to as $\mathrm{S} 1 \_650$ and so on.

Differential thermal analysis (DTA) measurements were performed on powdered samples with heating rate $10{ }^{\circ} \mathrm{C} / \mathrm{min}$ using Shimadzu DTG-60 analyzer and alumina reference.

X-ray diffraction (XRD) measurements were made to study the crystalline phases present in the glass ceramic samples with PANalytical X'Pert Pro diffractometer using $\mathrm{Cu} \mathrm{K} \alpha$ tube operated at $45 \mathrm{kV}$ and 40 mA. Crystallography Open Database was used for the interpretation of the observed peaks. [24-26]

The nanostructure of glass ceramics was investigated with transmission electron microscope (TEM) Tecnai G2 F20 operated at $200 \mathrm{kV}$. Samples were prepared as described in [27,28].

Photoluminescence (PL) was investigated by Andor CCD camera DU-401-BV coupled to Andor Technology spectrometer SR-303i-B. Xe lamp Hamamatsu C2577 and pulsed solid state laser Ekspla NT342/3UV with pulse duration of $4 \mathrm{~ns}$ and linewidth of $4.3 \mathrm{~cm}^{-1}$ were used as excitation sources. Luminescence decay times were measured by a photomultiplier tube with time resolution better than 20 ns and digital oscilloscope Tektronix TDS 684A. 
EPR spectra were recorded at $77 \mathrm{~K}$ using a conventional RE 13-06 X-band spectrometer $(9.07 \mathrm{GHz}$ with $0.01 \mathrm{GHz}$ accuracy). The magnetic field was calibrated using a polycrystalline DPPH standard with $\mathrm{g}=2.0036 \pm 0.0001$. Spectral analysis was carried out in EasySpin software [29].

\section{Results and discussion}

\subsection{Material characterization}

Fig. 1. shows the DTA curves of the studied samples. The glass transition temperature $\left(\mathrm{T}_{\mathrm{g}}\right)$ around $530{ }^{\circ} \mathrm{C}$ is similar for both compositions. Based on the XRD spectra in figure 2 the exothermic peak maximum at $\mathrm{T}_{\mathrm{C} 1}=595 \pm 5$ for $\mathrm{S} 1$ and $\mathrm{T}_{\mathrm{C} 1}=598 \pm 5$ for $\mathrm{S} 2$ has been assigned to the formation of $\mathrm{SrF}_{2}$ crystallites in the glass matrix. At temperatures above $700{ }^{\circ} \mathrm{C}$ complex silicate structures start to form.

S1 composition PG sample already contains small fraction of $\mathrm{SrF}_{2}$ nanocrystals, whereas the increased fluorine content $\mathrm{S} 2$ composition has led to significant crystallization of the matrix. Heat treatment near $\mathrm{T}_{\mathrm{C} 1}$ and above leads to the formation and further growth of $\mathrm{SrF}_{2}$ crystallites. Grain size estimations from Rietveld peak analysis are summarized in table 1 . Insets in figure 2 show typical TEM images of the samples heated at $650{ }^{\circ} \mathrm{C}$ verifying the $\mathrm{XRD}$ data and showing quite good uniformity in the $\mathrm{SrF}_{2}$ crystallite size distribution. $\mathrm{S} 1$ samples heated at $700{ }^{\circ} \mathrm{C}$ and above also contain various silicate phases such as nepheline $\left(\mathrm{NaAlSiO}_{4}\right)$. For the additional peaks marked with asterisks in the $\mathrm{S} 1 \_800$ sample the closest match was a sodalite-like crystalline structure. In the S2 composition strontium feldspar suppresses the formation of $\mathrm{SrF}_{2}$ nanocrystals after $800{ }^{\circ} \mathrm{C}$ heat treatment.

\begin{tabular}{ccc} 
Sample & \multicolumn{2}{c}{$\mathrm{SrF}_{2}$ crystallite size, $\mathrm{nm}$} \\
& $\mathrm{S} 1 \quad \mathrm{~S} 2$ \\
\hline PG & $6.75 \pm 0.25$ & $10.39 \pm 0.46$ \\
600 & $21.36 \pm 0.74$ & $14.91 \pm 0.39$ \\
650 & $60.0 \pm 3.5$ & $23.3 \pm 1.7$ \\
700 & $117 \pm 18$ & \\
800 & & \\
\hline
\end{tabular}

Table $1 . \mathrm{SrF}_{2}$ crystallite size calculations from Rietveld spectral peak analysis.

Visually the samples can be characterized as colourless and transparent, which is confirmed by the transmittance measurements in figure 3. Significant loss in transparency is observed only after 1 hour long heat treatment above $650{ }^{\circ} \mathrm{C}$ where silicate structures start to form. The dips in transparency at 
approximately 400 and $460 \mathrm{~nm}$ can be attributed to the absorbance of $\mathrm{Eu}^{3+}$ ions present in the glass matrix due to the energy level ${ }^{7} \mathrm{~F}_{0} \rightarrow{ }^{5} \mathrm{~L}_{7}$ and ${ }^{7} \mathrm{~F}_{0} \rightarrow{ }^{5} \mathrm{D}_{3}$ transitions.

\subsection{EPR measurements}

The EPR spectra (fig. 4.) of the initial and heat treated samples have an intensive peak at $g_{\text {eff }} \approx 4.3$. This resonance is common in disordered media and is usually attributed to $\mathrm{Fe}^{3+}$ impurities present in the material. [30]

No additional resonances are observed in the S1_PG, which is to be expected as $\mathrm{Eu}^{3+}$ ions are not paramagnetic. A relatively broad, structured line at $\mathrm{g}_{\mathrm{eff}} \approx 2$ appears in the thermally treated $\mathrm{S} 1$ samples suggesting a reduction of $\mathrm{Eu}^{3+}$ ions to the ${ }^{2+}$ state. Comparison of the S1_650 and S1_800 EPR spectra indicates that the resulting signal is a superposition of at least two paramagnetic centres - a broad envelope curve superimposed by narrow lines. Previous studies of gadolinium doped oxyfluoride GCs containing $\mathrm{CaF}_{2}, \mathrm{SrF}_{2}$ and $\mathrm{BaF}_{2}$ crystallites have shown that the EPR spectra can be satisfactorily simulated with parameter values for $\mathrm{Gd}^{3+}$ centres observed in the respective single crystal. [31,32]

S-state ions with $[\mathrm{Xe}] 4 \mathrm{f}^{7}$ electron configuration $\left(\mathrm{Gd}^{3+}, \mathrm{Eu}^{2+}\right)$ are known to produce EPR spectra with fine structure centered at $g=1.99$ in cubic crystals of $\mathrm{CaF}_{2}, \mathrm{SrF}_{2}, \mathrm{BaF}_{2}$ and $\mathrm{ScF}_{3}$. [33-40] Zero field splitting (ZFS) of the ground state leads to an EPR spectrum consisting of seven major fine-structure lines. Hyperfine structure interaction with nuclear spin $I=5 / 2$ of europium isotopes ${ }^{151} \mathrm{Eu}$ and ${ }^{153} \mathrm{Eu}$ results in further splitting of fine structure components. Thus, the resulting Spin-Hamiltonian necessary to interpret an effective spin $S=7 / 2$ system resonance positions in a cubic crystalline field is:

$H=g \beta B S+\frac{b_{4}}{60}\left(O_{4}^{0}+5 O_{4}^{4}\right)+A_{i} S I$

where $\beta$ is the Bohr magneton, $O_{m}{ }^{n}$ - spin operators and $A$-the hyperfine structure interaction constant. A more detailed explanation of spin-Hamiltonian formalism is given in [41].

The EPR signal of $\mathrm{Eu}^{2+}$ in a single crystal would yield a set of many angularly dependent resonance positions, whereas in polycrystalline media all orientations are averaged out resulting in a complex 
spectrum. Fig. 5. shows a comparison of the EPR spectra from S1_650 and S1_800 GCs with polycrystalline $\mathrm{SrF}_{2}: \mathrm{Eu}^{2+}$. The spectra of $\mathrm{S}_{-} \_50$ and $\mathrm{SrF}_{2}: \mathrm{Eu}^{2+}$ samples agree well with each meaning that the newly observed signal in $\mathrm{GCs}$ treated at $650{ }^{\circ} \mathrm{C}$ is due to the precipitation of $\mathrm{SrF}_{2}$ nanocrystals in the glass matrix, however, in GCs the signal intensity (and, therefore, the responsible paramagnetic centre ammount) is approximately 3 orders of magnitude lower. The resonance positions of S1_800 differ and thus could be associated with the formation of other crystalline phases in the material.

Simulation with spin-Hamiltonian parameter values $g=1.992, b_{4}=-45 \cdot 10^{-4} \mathrm{~cm}^{-1}, \mathrm{~A}_{151 \mathrm{Eu}}=-34 \cdot 10^{-4} \mathrm{~cm}^{-}$ ${ }^{1}, \mathrm{~A}_{153 \mathrm{Eu}}=-15 \cdot 10^{-4} \mathrm{~cm}^{-1}$ observed in cubic $\mathrm{Eu}^{2+}$ centre in single crystalline $\mathrm{SrF}_{2}$ [34] reproduces the wide envelope curve visible in our polycrystalline sample. As mentioned before, in GCs this signal is less pronounced compared to the narrow line signal caused by other paramagnetic centres.

EPR spectra in europium doped polycrystalline sulphides have shown resonances in approximately 200 Gauss range similarly to the narrow line structure we observe here. [15] In figure 6 this limited magnetic field range is simulated by a significantly smaller ZFS parameter and spin-Hamiltonian:

$$
H=g \beta B S+\frac{1}{3} b_{2}^{0} O_{2}^{0}+A_{i} S I
$$

The S1_650 and S1_800 EPR spectra have with similar hyperfine and ZFS parameter values as shown in table 2, however, the resonance positions are shifted in respect with each other requiring a slightly smaller $g$ for the S1_650. The cause for this $g$-shift could be due to a different chemical environment around $\mathrm{Eu}^{2+}$ ions in samples heated at high temperatures. Based on a study of $\mathrm{Mn}^{2+}$ and $\mathrm{Eu}^{2+}$ ions in microcrystalline chlorides [42], local symmetry change and the significant reduction in ZFS parameter values could be an indication that a majority of $\mathrm{Eu}^{2+}$ ions are located on the surfaces of crystallites. We have tried oxidizing europium ions on the surfaces by heating the polycrystalline $\mathrm{SrF}_{2}: \mathrm{Eu}^{2+}$ in $\mathrm{F}_{2}$ gas, however, intensity ratio change of the two signals was not observed. A more detailed defect model, therefore, requires further studies.

\begin{tabular}{ccc} 
& S1_650 & S1_800 \\
\hline$g$ & $1.978 \pm 0.002$ & $1.992 \pm 0.002$ \\
$b_{2}{ }^{0}, 10^{-4} \mathrm{~cm}^{-1}$ & $15 \pm 5$ & $10 \pm 5$ \\
$A_{15 I E u}, 10^{-4} \mathrm{~cm}^{-1}$ & $-34 \pm 1$ & $-33 \pm 1$ \\
$A_{153 E u}, 10^{-4} \mathrm{~cm}^{-1}$ & $-15 \pm 1$ & $-15 \pm 1$ \\
\hline
\end{tabular}


Table 2. Spin-Hamiltonian parameters used for simulations in figure 6.

EPR spectra of the S2 composition are shown in figure 4.b. All samples including the S2_PG have wide curves throughout the spectrum indicating the presence of europium in the divalent state already in the initial sample. The most prominent features of the spectra at $g_{\text {eff }} \approx 6.0,2.8$ and 2.0 coincide well with studies made for other glass systems doped with $\mathrm{Eu}^{2+} .[16-18]$ In general, Eu ${ }^{2+}$ spectra in disordered systems can be simulated by taking a broad distribution in second order ZFS parameter values. [43] In S2 samples the EPR spectra detect disordered local structure around $\mathrm{Eu}^{2+}$ at all heat treatment temperatures. For the S2_800 sample an additional structureless band superimposes the "glassy" spectrum at $g_{\text {eff }} \approx 2.0$, which indicates incorporation of $\mathrm{Eu}^{2+}$ ions in some crystalline phases.

To summarize the EPR results, the $\mathrm{Eu}^{2+}$ signal in $\mathrm{S} 1$ composition is detected only after the heat treatment of PG and the signal intensity increases significantly at high heating temperatures. Although the S2 composition is self-crystallized, the EPR signal comes from $\mathrm{Eu}^{2+}$ ions in the glassy state, not from $\mathrm{SrF}_{2}$ nanocrystals as could be expected. The incorporation of $\mathrm{Eu}^{2+}$ in the $\mathrm{SrF}_{2}$ crystalline phase after additional heat treatment is not observed, which could be due to unsuitable chemical environment around the $\mathrm{Eu}^{2+}$ ions (europium ions in the amorphous phase are probably coordinated by oxygen ligands). The decreased overall crystallinity of the $\mathrm{S} 2$ composition in comparison to $\mathrm{S} 1$ as visible from TEM images in Fig. 2 could also contribute to this effect.

\subsection{PL studies}

PL measurements of the samples under $394 \mathrm{~nm}$ Xe lamp excitation in figure 7 show characteristic $\mathrm{Eu}^{3+}$ luminescence. The significant decrease in the $\mathrm{R} / \mathrm{O}$ ratio after the heat treatment of both samples is proof of efficient incorporation of $\mathrm{Eu}^{3+}$ ions in the $\mathrm{SrF}_{2}$ crystalline phase. As discussed in [3,10-12,44-47] the electric dipole transition ${ }^{5} \mathrm{D}_{0} \rightarrow{ }^{7} \mathrm{~F}_{2}$ becomes forbidden in centrosymmetric environment and thus in high symmetry crystal fields $\mathrm{Eu}^{3+}$ luminescence is shifted to orange spectral region. In agreement with the XRD data, the decreased value of initial R/O ratio also suggests the increased crystallinity of the S2_PG sample. 
PL spectra under $350 \mathrm{~nm}$ laser excitation are shown in figure 8. The S1_PG sample barely exhibits any $\mathrm{Eu}^{2+}$ luminescence, whereas the intensive blue emission from S2_PG and the EPR spectra in fig.4.b confirms this sample's abundance with $\mathrm{Eu}^{2+}$ ions. The reduction of europium after the heat treatment of S1 samples is observable from the intensification of $\mathrm{Eu}^{2+}$ emission. The S1_650 sample shows a low signal/noise ratio, which is significantly improved after sample treatment at $700-800{ }^{\circ} \mathrm{C}$. This means that $\mathrm{Eu}^{3+} \rightarrow \mathrm{Eu}^{2+}$ reduction is more efficient at relatively high temperatures when silicate structures start to form. Particularly the band at approximately $550 \mathrm{~nm}$ in $\mathrm{S} 1 \_700$ could be associated with $\mathrm{Eu}^{2+}$ ions in the $\mathrm{NaAlSiO}_{4}$ phase as studies of polycrystalline samples have shown similar results. [48,49] Luminescence band with maximum in the near UV region, which dominates the PL spectrum of the S1_800 sample must be due to additional sodalite-like crystalline phase present in the material as suggested from the XRD results. In the $\mathrm{S} 2$ composition a change in $\mathrm{Eu}^{2+}$ luminescence is observed only after heat treatment at $700{ }^{\circ} \mathrm{C}$ and above. Literature data [50,51] and our XRD results suggest that the band at approximately $406 \mathrm{~nm}$ could be caused by $\mathrm{Eu}^{2+}$ ions in strontium feldspar type phase.

Samples of both compositions heat treated at $650{ }^{\circ} \mathrm{C}$ are compared with polycrystalline $\mathrm{SrF}_{2}: \mathrm{Eu}^{2+}$ in figure 9. Both GCs have similarly sized $\mathrm{SrF}_{2}$ crystallites $(\approx 20 \mathrm{~nm})$ and no additional crystalline phases present in the glass matrix. $\mathrm{SrF}_{2}: \mathrm{Eu}^{2+}$ powder exhibits a relatively narrow and intense spectral band peaking at $418 \mathrm{~nm}$ similarly as observed in recent studies of $\mathrm{SrF}_{2}$ :Eu phosphors. [13,52,53] The broader blue emission of the S1 and S2 samples, therefore, could be a superposition coming from $\mathrm{Eu}^{2+}$ ions in the glassy as well as crystalline phases. As already discussed in the EPR section, the $\mathrm{SrF}_{2}$ : $\mathrm{Eu}^{2+}$ signal in the S1 composition samples is barely detectable from the EPR measurements, therefore, its contribution to the luminescence spectra is expected to be insignificant. The observed EPR signal and other studies of $\mathrm{Eu}^{2+}$ luminescence in glasses $[19,22]$ clearly shows that the broad band of S2_650 originates from $\mathrm{Eu}^{2+}$ ions in the glass matrix.

The differences in S1 and S2 are, of course, related to the chemical composition of samples. The S2 samples are richer in fluorine content, which can lead to phase separation and rapid crystallization of the melt upon casting. Previous study in oxyfluoride glasses containing $\mathrm{CaF}_{2}$ suggests, that the increased fluorine anion content also enhances $\mathrm{Eu}^{3+} \rightarrow \mathrm{Eu}^{2+}$ conversion as well as leads to higher symmetry around 
$\mathrm{Eu}^{3+}$ ions. [19] To gain more insight on this, we synthesized an additional sample with S1 composition by substituting $5 \%$ of $\mathrm{Na}_{2} \mathrm{CO}_{3}$ with $\mathrm{NaF}$. As expected, a more significant crystallization upon quenching as well as $\mathrm{Eu}^{3+} \rightarrow \mathrm{Eu}^{2+}$ reduction was observed compared to S1.

In general, there are two main theories that explain the reduction of europium in materials prepared in air atmosphere. The charge compensation model describes hosts containing $\mathrm{M}^{2+}\left(\mathrm{M}^{2+}=\mathrm{Ca}^{2+}, \mathrm{Sr}^{2+}, \mathrm{Ba}^{2+}\right)$, where the phenomenon $\mathrm{Eu}^{3+} \rightarrow \mathrm{Eu}^{2+}$ is a consequence of necessary charge compensation as described in [22]. The optical basicity model, on the other hand, calculates the electron density carried by oxygen depending on the sample composition and is considered the main reduction mechanism in glasses. $\mathrm{Eu}^{2+}$ ions are favoured over $\mathrm{Eu}^{3+}$ in glasses below a critical optical basicity value. [19,54]

Our investigations of the $\mathrm{S} 1$ samples suggest that the primary reduction mechanism for europium is due to the required charge compensation upon precipitation of $\mathrm{SrF}_{2}$ crystalline phase in the matrix. The weak EPR signal detected in the corresponding GCs is similar to polycrystalline $\mathrm{SrF}_{2}: \mathrm{Eu}^{2+}$ and, therefore, originates from divalent europium in the $\mathrm{SrF}_{2}$ crystalline phase. The $\mathrm{Eu}^{3+} \rightarrow \mathrm{Eu}^{2+}$ transition efficiency is improved at higher heating temperatures where besides the characteristic EPR signal also pronounced $\mathrm{Eu}^{2+}$ luminescence spectra can be observed. Our results are consistent with theoretical work on geological samples [55] where $\mathrm{Eu} \rightarrow \mathrm{Eu}^{2+}$ reduction efficiency was increased at higher temperatures.

Although the S2 sample is already self-crystallized and self-reduced, the observed EPR signal comes from $\mathrm{Eu}^{2+}$ ions in the glass matrix. Thus we can corroborate, that $\mathrm{Eu}^{3+} \rightarrow \mathrm{Eu}^{2+}$ transition in the glassy state is promoted by the increased average electronegativity of the local environment around europium ions and can be achieved by increasing the fluorine content in the composition.

\section{Conclusions}

Transparent aluminosilicate oxyfluoride glass ceramics containing $\mathrm{SrF}_{2}$ crystallites and europium ions have been prepared by the melt quenching technique in air atmosphere. Significant decrease of the ${ }^{5} \mathrm{D}_{0} \rightarrow{ }^{7} \mathrm{~F}_{2}$ and ${ }^{5} \mathrm{D}_{0} \rightarrow{ }^{7} \mathrm{~F}_{1}$ transition intensity ratio is observed reflecting efficient incorporation of trivalent rare earth ions in the high symmetry environment of the crystalline phase. For the first time 
europium reduction by the heat treatment method of the precursor glass has been observed by EPR spectroscopy. Visible impact on the luminescence properties of europium doped glass-ceramics is observable after relatively higher heat treatment temperatures where $\mathrm{Eu}^{3+} \rightarrow \mathrm{Eu}^{2+}$ reduction is more efficient. In glass ceramics, which are obtained self-reduced upon casting the EPR signal and the corresponding blue luminescence originates mainly from $\mathrm{Eu}^{2+}$ ions in the glass matrix.

\section{Acknowledgements.}

Authors thank prof. U. Rogulis for valuable discussions and suggestions and Dr. Krisjanis Smits for TEM measurements. Financial support provided by Scientific Research Project for Students and Young Researchers Nr. SJZ/2016/3 realized at the Institute of Solid State Physics, University of Latvia is greatly acknowledged. Institute of Solid State Physics, University of Latvia as the Center of Excellence has received funding from the European Union's Horizon 2020 Framework Programme H2020WIDESPREAD-01-2016-2017-TeamingPhase2 under grant agreement No. 739508, project CAMART²

\section{References}

[1] P.P. Fedorov, A.A. Luginina, A.I. Popov, Transparent oxyfluoride glass ceramics, J. Fluor. Chem. 172 (2015) 22-50. doi:10.1016/j.jfluchem.2015.01.009.

[2] S. Ouyang, W. Zhang, Z. Zhang, Y. Zhang, Near-Green-Emitting Tb ${ }^{3+}$-Doped Transparent Glass Ceramics Containing $\mathrm{Ba}_{2} \mathrm{LaF}_{7}$ Nanocrystals for Application in White Light-Emitting Diodes, J. Appl. Spectrosc. 83 (2016) 277-282. doi:10.1007/s10812-016-0281-6.

[3] H. Jin, Z. Mo, X. Zhang, L. Yuan, M. Yan, L. Li, Luminescent properties of $\mathrm{Eu}^{3+}$-doped glass ceramics containing $\mathrm{BaCl}_{2}$ nanocrystals under NUV excitation for White LED, J. Lumin. 175 (2016) 187-192. doi:10.1016/j.jlumin.2016.03.002.

[4] M. Kemere, J. Sperga, U. Rogulis, G. Krieke, J. Grube, Luminescence properties of Eu, RE ${ }^{3+}$ $(\mathrm{RE}=\mathrm{Dy}, \mathrm{Sm}, \mathrm{Tb})$ co-doped oxyfluoride glasses and glass-ceramics, J. Lumin. 181 (2017) 2530. doi:10.1016/j.jlumin.2016.08.062.

[5] C.R. Li, S.F. Li, Y.Y. Guo, X.Y. Zhou, J.C. Sun, Y. Song, et al., White light emission of Dy ${ }^{3+}$ doped and $\mathrm{Dy}^{3+}: \mathrm{Yb}^{3+}$-codoped oxyfluoride glass ceramics under 388-nm excitation, 340 (2015). doi:10.1080/09500340.2015.1061060.

[6] L.Q. Yao, G.H. Chen, H.J. Zhong, S.C. Cui, F. Li, J.Y. Gan, Enhanced Luminescent Properties in $\mathrm{Tm}^{3+} / \mathrm{Dy}^{3+}$ Transparent Phosphate Glass Ceramic, in: MATEC Web Conf., 2016.

[7] Z. Zhang, Y. Zhang, Z. Feng, W. Cheng, H. Xia, X. Zhang, Luminescent properties of $\mathrm{Ce}^{3+} /$ $\mathrm{Tb}^{3+}$ co-doped glass ceramics containing $\mathrm{YPO}_{4}$ nanocrystals for W-LEDs, J. Rare Earths. 34 (2016) 464-469. doi:10.1016/S1002-0721(16)60050-9.

[8] D. Chen, W. Xiang, X. Liang, J. Zhong, H. Yu, M. Ding, et al., Advances in transparent glassceramic phosphors for white light-emitting diodes-A review, J. Eur. Ceram. Soc. 35 (2015) 859-869. doi:10.1016/j.jeurceramsoc.2014.10.002. 
[9] K. Binnemans, Interpretation of europium(III) spectra, Coord. Chem. Rev. 295 (2015) 1-45. doi:10.1016/j.ccr.2015.02.015.

[10] M. Walas, T. Lewandowski, A. Synak, M. Lapinski, W. Sadowski, B. Koscielska, Eu ${ }^{3+}$ doped tellurite glass ceramics containing $\mathrm{SrF}_{2}$ nanocrystals: Preparation, structure and luminescence properties, J. Alloys Compd. 696 (2017) 619-626. doi:10.1016/j.jallcom.2016.11.301.

[11] D. Chen, Y. Yu, P. Huang, H. Lin, Z. Shan, Y. Wang, Color-tunable luminescence of Eu ${ }^{3+}$ in $\mathrm{LaF}_{3}$ embedded nanocomposite for light emitting diode, Acta Mater. 58 (2010) 3035-3041. doi:10.1016/j.actamat.2010.01.035.

[12] D. Chen, Y. Zhou, Z. Wan, P. Huang, H. Yu, H. Lu, et al., Enhanced upconversion luminescence in phase-separation-controlled crystallization glass ceramics containing $\mathrm{Yb} / \mathrm{Er}(\mathrm{Tm}): \mathrm{NaLuF}_{4}$ nanocrystals, J. Eur. Ceram. Soc. 35 (2015) 2129-2137. doi:10.1016/j.jeurceramsoc.2015.01.021.

[13] M.Y.A. Yagoub, H.C. Swart, L.L. Noto, J.H. O'Connel, M.E. Lee, E. Coetsee, The effects of Eu-concentrations on the luminescent properties of $\mathrm{SrF}_{2}:$ Eu nanophosphor, J. Lumin. 156 (2014) 150-156. doi:10.1016/j.jlumin.2014.08.014.

[14] V. Liepina, D. Millers, K. Smits, Tunneling luminescence in long lasting afterglow of $\mathrm{SrAl}_{2} \mathrm{O}_{4}$ :Eu,Dy, J. Lumin. 185 (2017) 151-154. doi:10.1016/j.jlumin.2017.01.011.

[15] P.F. Smet, J.E. Van Haecke, F. Loncke, H. Vrielinck, F. Callens, D. Poelman, Anomalous photoluminescence in BaS:Eu, Phys. Rev. B - Condens. Matter Mater. Phys. 74 (2006) 1-9. doi:10.1103/PhysRevB.74.035207.

[16] S. Schweizer, G. Corradi, A. Edgar, J.-M. Spaeth, EPR of Eu ${ }^{2+}$ in $\mathrm{BaBr}_{2}$ crystals and fluorobromozirconate glass ceramics, J. Phys. Condens. Matter. 13 (2001) 2331-2338. doi:10.1088/0953-8984/13/10/323.

[17] H. Ebendorff-Heidepriem, D. Ehrt, Electron spin resonance spectra of $\mathrm{Eu}^{2+}$ and $\mathrm{Tb}^{4+}$ ions in glasses, J. Phys. Condens. Matter. 11 (1999) 7627. doi:10.1088/0953-8984/11/39/317.

[18] D. Furniss, E.A. Harris, D.B. Hollis, EPR of $\mathrm{Gd}^{3+}$ and $\mathrm{Eu}^{2+}$ in fluorozirconate glasses, J. Phys. C Solid State Phys. 20 (1987) L147-L150. doi:10.1088/0022-3719/20/10/002.

[19] Z. Lin, H. Zeng, Y. Yang, X. Liang, G. Chen, L. Sun, The effect of fluorine anions on the luminescent properties of Eu-Doped oxyfluoride aluminosilicate glasses, J. Am. Ceram. Soc. 93 (2010) 3095-3098. doi:10.1111/j.1551-2916.2010.04067.x.

[20] Q. Luo, X. Qiao, X. Fan, S. Liu, H. Yang, X. Zhang, Reduction and luminescence of europium ions in glass ceramics containing $\mathrm{SrF}_{2}$ nanocrystals, J. Non. Cryst. Solids. 354 (2008) 46914694. doi:10.1016/j.jnoncrysol.2008.07.019.

[21] Q. Luo, X. Qiao, X. Fan, X. Zhang, Luminescence properties of $\mathrm{Eu}^{2+}$-doped glass ceramics containing $\mathrm{SrF}_{2}$ nanocrystals, J. Am. Ceram. Soc. 93 (2010) 2684-2688. doi:10.1111/j.15512916.2010.03756.x.

[22] C. Zhu, D. Wu, Y. Zhang, M. Zhang, Y. Yue, Composition dependence of the optical and structural properties of Eu-doped oxyfluoride glasses, J. Alloys Compd. 632 (2015) 291-295. doi:10.1016/j.jallcom.2015.01.207.

[23] K. Biswas, A.D. Sontakke, R. Sen, K. Annapurna, Luminescence properties of dual valence Eu doped nano-crystalline $\mathrm{BaF}_{2}$ embedded glass-ceramics and observation of $\mathrm{Eu}^{2+} \rightarrow \mathrm{Eu}^{3+}$ energy transfer., J. Fluoresc. 22 (2012) 745-52. doi:10.1007/s10895-011-1010-4.

[24] S. Graulis, D. Chateigner, R.T. Downs, A.F.T. Yokochi, M. Quirós, L. Lutterotti, et al., 
Crystallography Open Database - An open-access collection of crystal structures, J. Appl. Crystallogr. 42 (2009) 726-729. doi:10.1107/S0021889809016690.

[25] S. Gražulis, A. Daškevič, A. Merkys, D. Chateigner, L. Lutterotti, M. Quirós, et al., Crystallography Open Database (COD): An open-access collection of crystal structures and platform for world-wide collaboration, Nucleic Acids Res. 40 (2012) 420-427. doi:10.1093/nar/gkr900.

[26] R.T. Downs, M. Hall-Wallace, The American Mineralogist crystal structure database, Am. Mineral. 88 (2003) 247-250.

[27] K. Smits, A. Sarakovskis, L. Grigorjeva, D. Millers, J. Grabis, The role of Nb in intensity increase of Er ion upconversion luminescence in zirconia, J. Appl. Phys. 115 (2014) 1-9. doi:10.1063/1.4882262.

[28] L. Grigorjeva, D. Millers, K. Smits, A. Zolotarjovs, Gas sensitive luminescence of ZnO coatings obtained by plazma electrolytic oxidation, Sensors Actuators, A Phys. 234 (2015) 290-293. doi:10.1016/j.sna.2015.09.018.

[29] S. Stoll, A. Schweiger, EasySpin, a comprehensive software package for spectral simulation and analysis in EPR, J. Magn. Reson. 178 (2006) 42-55.

[30] C.M. Brodbeck, R.R. Bukrey, Model calculations for the coordination of $\mathrm{Fe}^{3+}$ and $\mathrm{Mn}^{2+}$ ions in oxide glasses, Phys. Rev. B. 24 (1981) 2334-2342.

[31] A. Fedotovs, A. Antuzevics, U. Rogulis, M. Kemere, R. Ignatans, Electron paramagnetic resonance and magnetic circular dichroism of $\mathrm{Gd}^{3+}$ ions in oxyfluoride glass-ceramics containing $\mathrm{CaF}_{2}$ nanocrystals, J. Non. Cryst. Solids. 429 (2015) 118-121. doi:10.1016/j.jnoncrysol.2015.08.036.

[32] A. Antuzevics, M. Kemere, R. Ignatans, Local structure of gadolinium in oxyfluoride glass matrices containing $\mathrm{SrF}_{2}$ and $\mathrm{BaF}_{2}$ crystallites, J. Non. Cryst. Solids. 449 (2016). doi:10.1016/j.jnoncrysol.2016.07.015.

[33] J.M. Baker, B. Bleaney, W. Hayes, Paramagnetic Resonance of S-State Ions in Calcium Fluoride, Proc. R. Soc. A Math. Phys. Eng. Sci. 247 (1958) 141-151. doi:10.1098/rspa.1958.0174.

[34] R.S. Title, The cubic field splitting of the $\mathrm{Eu}^{++} \mathrm{EPR}$ spectrum in the alkaline earth fluorides, Phys. Lett. 6 (1963) 13-14.

[35] J. Sierro, Paramagnetic resonance of $\mathrm{Gd}^{3+}$ in $\mathrm{SrF}_{2}$ and $\mathrm{BaF}_{2}$, Phys. Lett. 4 (1963) 178-180. doi:10.1093/jicru/ndp028.

[36] W.-Q. Yang, Y. Zhang, Y. Lin, W.-C. Zheng, Spin-Hamiltonian parameters for the tetragonal centers in $\mathrm{CaF}_{2}$ and $\mathrm{SrF}_{2}$ crystals, J. Magn. Reson. 227 (2013) 62-65.

doi:10.1016/j.jmr.2012.12.003.

[37] C. Yang, S. Lee, A.J. Bevolo, Investigations of the weak trigonal $\mathrm{Gd}^{3+}$ ESR center in alkalineearth fluoride crystals, Phys. Rev. B. 13 (1976) 2762-2767.

[38] S. Lee, C. Yang, A.J. Bevolo, Investigations of the new trigonal $\mathrm{Gd}^{3+}$ ESR center produced in irradiated alkaline-earth fluoride crystals, Phys. Rev. B. 10 (1974) 4515-4522.

[39] C. Yang, S. Lee, A.J. Bevolo, Investigations of two trigonal $\left(T_{1}\right.$ and $\left.T_{2}\right) \mathrm{Gd}^{3+}$ ESR centers in treated alkaline-earth-fluoride crystals, Phys. Rev. B. 12 (1975) 4687-4694.

[40] A. Antuzevics, U. Rogulis, A. Fedotovs, D. Berzins, V.N. Voronov, J. Purans, EPR Study of 
$\mathrm{Gd}^{3+}$ local structure in $\mathrm{ScF}_{3}$ crystal with negative thermal expansion coefficient, Phys. Scr. 90 (2015). doi:10.1088/0031-8949/90/11/115801.

[41] A. Abragam, B. Bleaney, Electron Paramagnetic Resonance of Transition Ions, in: Electron Paramagn. Reson. Transit. Ions, 1970: pp. 4, 42, 133-163, 398-406, 417-430-547, 583-599. doi:10.1017/CBO9781107415324.004.

[42] V.M. Maevskii, E. V Mozdor, A.B. Roitsin, EPR of $\mathrm{Mn}^{2+}$ and $\mathrm{Eu}^{2+}$ Ions in the Bulk and on the Surface of $\mathrm{A}_{\mathrm{I}} \mathrm{B}_{\mathrm{VII}}$ Type Single- and Microcrystals, Appl. Magn. Reson. 18 (2000) 549-558.

[43] C.M. Brodbeck, L.E. Iton, The EPR spectra of $\mathrm{Gd}^{3+}$ and $\mathrm{Eu}^{2+}$ in glassy systems, J. Chem. Phys. 83 (1985) 4285. doi:10.1063/1.449041.

[44] T.T. Van Tran, T.M.D. Cao, Q.V. Lam, V.H. Le, Emission of $\mathrm{Eu}^{3+}$ in $\mathrm{SiO}_{2}-\mathrm{ZnO}$ glass and $\mathrm{SiO}_{2}-\mathrm{SnO}_{2}$ glass-ceramic: Correlation between structure and optical properties of $\mathrm{Eu}^{3+}$ ions, $\mathrm{J}$. Non. Cryst. Solids. 459 (2017) 57-62. doi:10.1016/j.jnoncrysol.2016.12.040.

[45] K. Smits, D. Millers, A. Zolotarjovs, R. Drunka, M. Vanks, Luminescence of Eu ion in alumina prepared by plasma electrolytic oxidation, Appl. Surf. Sci. 337 (2015) 166-171. doi:10.1016/j.apsusc.2015.02.085.

[46] J. Papan, D. Jovanovic, K. Vukovic, K. Smits, V. Dordevic, M. Dramicanin, Europium(III)doped $\mathrm{A}_{2} \mathrm{Hf}_{2} \mathrm{O}_{7}(\mathrm{~A}=\mathrm{Y}, \mathrm{Gd}, \mathrm{Lu})$ nanoparticles: Influence of annealing temperature, europium(III) concentration and host cation on the luminescent properties, Opt. Mater. (Amst). 61 (2016) 68-76. doi:10.1016/j.optmat.2016.04.007.

[47] K. Smits, L. Grigorjeva, D. Millers, A. Sarakovskis, A. Opalinska, J.D. Fidelus, et al., Europium doped zirconia luminescence, Opt. Mater. (Amst). 32 (2010) 827-831. doi:10.1016/j.optmat.2010.03.002.

[48] D.S. Jo, Y. Luo, K. Senthil, K. Toda, B.S. Kim, T. Masaki, et al., Synthesis and photoluminescence properties of new $\mathrm{NaAlSiO}_{4}: \mathrm{Eu}^{2+}$ phosphors for near-UV white LED applications, Opt. Mater. (Amst). 34 (2012) 696-699. doi:10.1016/j.optmat.2011.10.004.

[49] Y. GUO, X. YU, J. LIU, X. YANG, Photoluminescence of $\mathrm{Eu}^{2+}$-activated $\mathrm{Na}_{1-\mathrm{x}} \mathrm{Al}_{1-\mathrm{x}} \mathrm{Si}_{1+\mathrm{x}} \mathrm{O}_{4}$ upon UV excitation, J. Rare Earths. 28 (2010) 34-36. doi:10.1016/S1002-0721(09)60045-4.

[50] J. Chen, Y. Liu, H. Liu, H. Ding, M. Fang, Z. Huang, Tunable $\mathrm{SrAl}_{2} \mathrm{Si}_{2} \mathrm{O}_{8}$ : Eu phosphor prepared in air via valence state-controlled means, Opt. Mater. (Amst). 42 (2015) 80-86. doi:10.1016/j.optmat.2014.12.023.

[51] Z. Wang, Y. Wang, P. Zhang, X. Fan, G. Qian, Tunable afterglow color in $\mathrm{Eu}^{2+}$ and $\mathrm{Dy}^{3+}$ coactivated alkaline earth feldspar solid solutions phosphors, J. Lumin. 124 (2007) 140-142. doi:10.1016/j.jlumin.2006.02.015.

[52] M.Y.A. Yagoub, H.C. Swart, P. Bergman, E. Coetsee, Enhanced $\operatorname{Pr}^{3+}$ photoluminescence by energy transfer in $\mathrm{SrF}_{2}: \mathrm{Eu}^{2+}, \mathrm{Pr}^{3+}$ phosphor, 25204 (2016). doi:10.1063/1.4941833.

[53] N.S. Ugemuge, A.M. Muke, A.A. Muley, C.S. Gayner, S. V Moharil, Synthesis of $\mathrm{SrF}_{2}: \mathrm{Eu}^{2+}$ up conversion phosphors, 3 (2012) 67-68.

[54] R.R. Reddy, Y. Nazeer Ahammed, K. Rama Gopal, P. Abdul Azeem, T.V.R. Rao, Correlation between optical basicity, electronegativity and electronic polarizability for some oxides and oxysalts, Opt. Mater. (Amst). 12 (1999) 425-428. doi:10.1016/S0925-3467(98)00083-4.

[55] M. Bau, Rare-Earth Element Mobility During Hydrothermal and Metamorphic Fluid Rock Interaction and the Significance of the Oxidation-State of Europium, Chem. Geol. 93 (1991) 219-230. doi:10.1016/0009-2541(91)90115-8. 
Figure 1. DTA curves of the studied compositions.

Figure 2. XRD spectra of (a) S1, (b) S2 composition samples. Insets show TEM images of samples heated at $650{ }^{\circ} \mathrm{C}$.

Figure 3. Transmittance of the studied samples. Insets show sample photos.

Figure 4. EPR spectra of (a) S1, (b) S2 composition samples.

Figure 5. Comparison of the $\mathrm{S} 1 \_650$ and $\mathrm{S} 1 \_800 \mathrm{EPR}$ spectra with polycrystalline $\mathrm{SrF}_{2}: \mathrm{Eu}^{2+}$ sample. Simulation curve corresponds to cubic $\mathrm{Eu}^{2+}$ observed in single crystal $\mathrm{SrF}_{2}$ [34].

Figure 6. Simulations of the EPR spectra of S1_650 and S1_800 samples with spin-Hamiltonian (2) and parameter values from table 2 .

Figure 7. PL spectra of the samples under $394 \mathrm{~nm}$ Xe lamp excitation. Insets show the calculated R/O values.

Figure 8. PL spectra of (a) S1, (b) S2 samples under $350 \mathrm{~nm}$ laser excitation.

Figure 9. PL comparison of S1_650 and S2_650 with polycrystalline $\mathrm{SrF}_{2}: \mathrm{Eu}^{2+}$ under $350 \mathrm{~nm}$ laser excitation. 